
\title{
$\begin{array}{ll}\text { Research Square } & \text { Preprints are preliminary reports that have not undergone peer review. } \\ \text { They should not be considered conclusive, used to inform clinical practice, } \\ \text { or referenced by the media as validated information. }\end{array}$ \\ Evaluation On The Safety of Anti-Platelet Agents In Patients With Acute Pancreatitis: A Retrospective Cohort Study
}

\section{Yin $\mathrm{Xu}$}

Changzhou No.2 people's Hospital Affiliated to Nanjing Medical University

\section{Jun Dong}

Changzhou No.2 people's Hospital Affiliated to Nanjing Medical University

Junling Fang

Changzhou No.2 people's Hospital Affiliated to Nanjing Medical University

\section{Yuhang Shen}

Changzhou No.2 people's Hospital Affiliated to Nanjing Medical University

\section{Zhu Chunfu ( $\nabla$ zcfmlm@njmu.edu.cn )}

Changzhou No.2 people's Hospital Affiliated to Nanjing Medical University

\section{Research Article}

\section{Keywords:}

Posted Date: February 9th, 2022

DOI: https://doi.org/10.21203/rs.3.rs-1287893/v1

License: (c) (i) This work is licensed under a Creative Commons Attribution 4.0 International License. Read Full License 


\section{Abstract}

Background: Anti-platelet drug has not been paid much attention in guidelines for the treatment of acute pancreatitis, especially in patients with cardiovascular disease and receiving anti-platelet therapy, and its safety hasn't been evaluated by any guidelines or studies.

Methods: A total of 904 patients with acute pancreatitis were enrolled in this cohort study, they were divided into Anti-platelet therapy group $(n=297)$ and non-Anti-platelet therapy group $(n=607)$. The primary result was the mortality in the $14^{\text {th }}$-day, $28^{\text {th }}$-day, and $90^{\text {th }}$-day. Adverse events during treatment included septic shock, respiratory tract infection, urinary tract infection, abdominal infection, bleeding, kidney damage, respiratory distress, cardiac dysfunction, liver dysfunction, and renal dysfunction. Kaplan-meier, propensity score matching (PSM), subsequently, cox regression and subgroup analysis were performed.

Results: The mortality rates were $9.55 \%$ vs $4.71 \%, P=0.012,13.34 \%$ vs $8.1 \%, P=0.02,16.14 \%$ vs $13.13 \%, P=0.235$, respectively, during the 14-day, 28-day, and 90-day follow-up periods. Risk ratio for death among anticoagulants versus non-anticoagulants after multivariate adjustment (HR=2.815,2.819, 95\% Cl:1.021-4.667,1.045-4.5

$83, p<0.05)$. According to the survival curves, there were significant differences in mortality after 14,28 , and 90 days between the anticoagulant and non-anticoagulant groups (log-rank $P<0.05$ ). After PSM, 297 pairs were identified, and there was no significant difference in the risk of death between the anticoagulant and nonanticoagulant groups (all $\mathrm{P}>0.05$ ).

Conclusions: Anti-platelet therapy is not superior to non-prophylactic anti-platelet therapy in terms of reducing mortality and adverse events in acute pancreatitis, and there is no statistically significant difference in mortality and adverse events in the cohort of cardiovascular patients using anti-platelet drugs compared with those without using anti-platelet drugs.

\section{Introduction}

Acute pancreatitis is characterized by acute onset and rapid change of disease conditions. Patients with mild acute pancreatitis account for $80 \%$, with the mortality rate of $1 \%-2 \%[1] .20 \%$ of patients with mild acute pancreatitis can develop to those with acute severe pancreatitis, and $10 \%-20 \%$ of patients with acute severe pancreatitis died from septic shock caused by persistent organ failure and systemic inflammatory response [2, 3]. According to the Atlanta Conference in 2012, the high risk of death caused by acute severe pancreatitis consisted of two stages, in the first week and the first month, death results from systemic inflammatory response (SIRS) and persistent organ failure, respectively[4]. The incidence of portal vein and splenic vein thrombosis in patients with acute pancreatitis is about $13 \%$, which can lead to liver failure, portal vein hypertension, spleen and intestinal necrosis in severe cases [5]. According to the guidelines, the use of thrombolytic drugs is not recommended because of the increased risk of bleeding after thrombolytic therapy. Anti-platelet drugs are the base of drugs for cardiovascular and cerebrovascular diseases, and the daily prophylactic use of anti-platelet drugs within the indication range in the cardiovascular and cerebrovascular disease population are recommended, however, the association between anti-platelet drug use and adverse events and outcomes in acute pancreatitis have been assessed by few studies or guideline. This study evaluated the difference of adverse events under the use of anti-platelet drugs and without the use of anti-platelet drugs in the course of the 
prognosis of acute pancreatitis, and explores the security of patients with acute pancreatitis to use anti-platelet in cardiovascular disease.

\section{Materials And Methods}

\subsection{Data Sources}

In this retrospective cohort study, the data of patients with acute pancreatitis were from Mimic-III, a large, singlecenter, public critical care database, which includes more than 40,000 ICU inpatients admitted to Beth Israel Deaconess Medical Center in Boston over a 14-year period from 2001 to 2012. To access this database, we passed relevant exams and were certified to access this database (number: 27714078). In this database, detailed information on ICU patient stays, including high-resolution monitoring data, therapeutic interventions including medications, discharge summaries, laboratory data, and radiology reports are contained. In terms of the International Classification of Diseases, the code of Acute Pancreatitis uses Version 9 (ICD-9) was 5770. We extracted clinical demographic characteristics, ICD-9 and other indicator codes, physiological indicators and laboratory tests, and the data was executed in mimic-IIl database through Structured Query Language (SQL). Supported by the Beth Israel Deaconess Medical Center (Boston, MA) and approved by the Institutional Review Board of MIT (Cambridge, MA), this study avoided informed consent and ethical requirements for patients because of the database and research design.

\subsection{Criteria for the diagnosis}

According to ICD-9 code 5770, 1216 patients with acute pancreatitis were retrieved. Only patients with first admission and first diagnosis of AP were included. Exclusion criteria :(1) Those who are less than 18 years old. (2) Those with chronic pancreatitis and pancreatic tumor. (3) Those with a history of severe immune system or coagulation disease. (4) Those whose return visit data i missed. (Figure 1)

\subsection{Variables of the data}

Variables included gender, height, weight, hypertension, diabetes, hyperlipidemia, chronic coronary atherosclerosis, coronary heart disease, hyperlipidemia, and whether invasive ventilation was performed. Laboratory materials included white blood cell count, platelet count, coagulation time, critical score (SAPS-II Score,Oasis Score,Sofa Score,GCS Score), complications include liver insufficiency, cardiac insufficiency, renal insufficiency, kidney injury, ARDS, abdominal infection, Respiratory infections, urinary tract infections, bleeding, septic shock, etc. Patients were treated with anti-platelet drugs (aspirin and clopidogrel). Variables of the result were the mortality after 14 days, mortality after 28 days, mortality after 90 days, and the incidence of adverse events.

\subsection{Statistical Analysis}

Statistical description and hypothesis testing: data were processed through the statistical software SPSS25.0 and R3.6.2 (SPSS, Chicago, Illinois, USA), which is internationally recognized. Descriptive statistics: KolmogorovSmirnov method was adopted to evaluate the characteristics of the distribution of the measurement data. Continuous data were presented as the median of the mean \pm standard deviation or quartile range, and then it was compared using either the student T-test or the Mann-Whitney U test. The categorical variables were 
expressed as numbers with percentages and compared using Pearson's $\chi 2$ or Fisher's exact test. Kaplan-meier curve was adopted to show the cumulative incidence of events, and log-rank test was adopted for comparison. Moreover, cox proportional regression analysis was used to determine the relationship between anticoagulant use and mortality. Event risk in model 1 was adjusted for age and sex, BMI, and was further adjusted for multiple clinically relevant variables in Model 2, including age, sex, BMI, hypertension, diabetes and hyperlipidemia, liver insufficiency, cardiac insufficiency, renal insufficiency, kidney damage, ARDS, abdominal infection, respiratory infection, urinary tract infection, bleeding, septic shock, white blood cell count, platelet count, coagulation time, critical score (Saps- II Score,Oasis Score,Sofa Score,GCS Score). To minimize selection bias and control for the potential confounding effects of differences in baseline data, a propensity score matching (PSM) analysis between the anticoagulant and non-anticoagulant groups has been adopted, with its proportion of 1:1, subsequently, propensity score was calculated through the binary logistic regression model. It has been observed that the uneven distribution of risk at baseline was mainly due to differences in age, platelet count, and Sofa score, as well as chronic coronary syndrome and coronary heart disease. Therefore, these four factors were incorporated into the PSM model. Finally, 297 pairs were identified, and their characteristics and outcomes were compared again after PSM, in the bilateral analysis, when $\mathrm{P}<0.05$, it was considered statistically significant.

\section{Results}

\subsection{Characteristics of the baseline}

904 patients were enrolled in this cohort, of whom 297 received anti-platelet therapy and 607 did not receive it, as shown in Table 1. Before the PSM method, there were statistically significant differences in age, platelet count, Sofa score, cardiovascular disease, mortality after 14 days, and mortality after 28 days between the two groups. $(p<0.05)$. There was no significant difference in liver insufficiency, cardiac insufficiency, renal insufficiency, kidney injury, ARDS, abdominal cavity infection, respiratory system infection, urinary tract infection, bleeding and septic shock between 2 groups ( $P>0.05$ ). After PSM, 297 patients receiving anti-platelet therapy were matched with 297 patients not receiving anti-platelet drugs with a proportion of 1:1 (Figure 1).

\subsection{Clinical Results}

The mortality rates after 14 days, 28 days and 90 days were $9.55 \%$ vs $4.71 \%, P=0.012,13.34 \%$ VS $8.01 \%, p=$ $0.02,16.14 \%$ VS13.13\%, $\mathrm{p}=0.235$ (table 1). Before PSM, it has also been shown in Kaplan-Meier curve (Figure 2) that there was a statistically significant difference in prognosis between two groups after 14 days and 28 days (log-rank $P=0.012$ and 0.02 , respectively). There was no significant difference between the two groups after 90 days (Log-rank $P=0.22$ ). After PSM, the demographic and confounding factors of 296 pairs became comparable (Table 1). After PSM, there was no significant difference in mortality and complication events between patients who took anti-platelet drugs and those who did not $(P>0.05)$ (Table 2). According to the Kaplan-meier curve (Figure 2), there was no significant difference in prognosis between these two groups on the 14 days, 28 days, and 90 days (log-rank $P=0.082,0.066$, and 0.39 , respectively).

\subsection{Relationship between anti-platelet therapy or non-anti-platelet therapy and efficacy}

As is vividly shown in Cox regression analysis (Table 3), compared with anti-platelet drugs, patients in the unadjusted model at 14 days $(\mathrm{HR}=2.063,95 \% \mathrm{Cl}: 1.150-3.701, \mathrm{P}=0.015)$ and 28 days $(\mathrm{HR}=1.702,95 \% \mathrm{Cl}: 1.079-$ $2.686, \mathrm{P}=0.022)$ presented an increased risk of death, even after multi-variable adjustment, and no anti-platelet 
medication after 14 days $(\mathrm{HR}=2.185,95 \% \mathrm{Cl}: 1.021-4.667, \mathrm{P}=0.044)$ or 28 days $(\mathrm{HR}=2.811,95 \% \mathrm{Cl}: 1.473-5.364, \mathrm{P}$ $=0.002$ ) were not associated with increased risk of death. After PSM, there was no statistically significant increase in the risk of death after 14 days and 28 days compared with patients using anti-platelet drug in the unadjusted model and adjusted COX model. $(P>0.05)$.

\subsection{Analysis of the subgroup}

In the acute pancreatitis subgroup analysis, stratified by gender, age, BMI, hypertension, diabetes and hyperlipidemia, liver insufficiency, heart insufficiency, renal insufficiency, kidney injury, ARDS, and cardiovascular disease, among patients in the stratified group with cardiovascular disease, the risk of death of patients without receiving anti-platelet drugs was 2.460 times higher than those receiving anti-platelet drugs $(P<0.05)$. There was no statistical significance in the other subgroups $(P>0.05)$. In patients with cardiovascular disease after PSM, the risk of death was similar for both anti-platelet and non-anti-platelet users $(P>0.05)$ (Table 4).

\section{Discussion}

In this study, no significant difference in mortality or complications were found in terms of acute pancreatitis between anti-platelet agents and those without anti-platelet agents, and these remained insignificant after PSM, multi-variable adjustment, and subgroup analysis, suggesting that anti-platelet use did not have a positive effect on the course of acute pancreatitis. Adverse events or mortality didn't increased after continuous use of antiplatelet agents in patients with acute pancreatitis in cardiovascular disease, and therefore should be continued according to guidelines for the course of the disease.

The treatment of acute pancreatitis, especially the treatment of SAP with multiple complications, is a complex process involving multiple disciplines such as surgery, gastroenterology, emergency department, intensive care medicine, infection department, interventional department, nutrition department and rehabilitation department, and the mode of multidisciplinary collaborative diagnosis and treatment should be adopted[7]. In the early treatment of acute pancreatitis, fluid therapy, analgesia and nutritional support, and treatment for etiology and early complications are included[8].

It has been suggested in previous studies that platelets play an important role in maintaining the integrity of blood vessel walls and in hemostasis, thrombosis and wound healing, furthermore, it is of vital importance in the process of blood coagulation by regulating hemostasis and coagulation generation. However, in addition, it has been proved in more and more studies that platelets are related to inflammatory response and can even participate in systemic inflammatory response syndrome [10-15]. Platelets and their products are directly or indirectly involved in the occurrence and development of inflammatory reactions, which may results from the fact that platelets can recognize pathogenic microorganisms related to inflammation and various signals generated during inflammation. Activated platelets can produce a large number of cytokines and chemokines, thus producing a variety of immune effects and regulatory functions [16]. There is no or low expression of CD40L on the surface of resting platelets. When invaded by pathogens, platelets are activated and can induce the expression of CD40L, which can subsequently act on endothelial cells and lymphocytes, triggering a variety of inflammatory reactions. Namely, the combination of CD 40 and CD40L activate various inflammatory cells to produce various pro-inflammatory factors such interleukin- 1 and interleukin-2, and simultaneously leads to the release of local adhesion molecules, including intercellular adhesion molecule-1, vascular cell adhesion 
molecule-1 and P-selectin, and regulates the chemoattraction and exudation of leukocytes to inflammatory sites, which is also a further participation in the inflammatory process $[17,18]$. After being stimulated by inflammation, platelets are activated and can produce and release a variety of chemical agonists that regulate inflammation, such as PF4, $\beta-T G$, MIP-1a, etc. Platelets directly or indirectly play an important role in the process of inflammation with the assistance of these cytokines/chemokines [19].

Until today, few studies have demonstrated the role of anti-platelet agents in acute pancreatitis. According to Akyazi et al, long-term pre-processing of aspirin preconditioning can prevent or improve certain hematologic, serological, and histological changes associated with AP. Guotao Lu et al. It is reported that the protection of acinar cells from necrosis in the early stage of AP plays a critical role in the pathologic process of AP. Aspirin reduces the level of COX in pancreatic tissue and protects pancreatic acinar cells from necrosis and reduces the severity of SAP. Clinically, aspirin may be a potential therapeutic intervention in the treatment of SAP [20]. According to a study in Taiwan, the risk for 5000 patients enrolled in a cohort study using aspirin developing acute pancreatitis was 8 times higher than those not taking aspirin [22]. Therefore, the use of anti-platelet drugs is controversial in clinic.

According to guidelines, patients with a history of atherosclerotic cardiovascular disease should receive aspirin for secondary prevention. For patients with atherosclerotic cardiovascular disease, clopidogrel ( $75 \mathrm{mg} /$ day) is recommended if they they are confirmed allergic to aspirin. A combination of anti-platelet agents (low-dose aspirin combined with a P2Y12 inhibitor) can be adopted for up to one year after the appearance of acute coronary syndrome, and there may be greater benefits if prolonging the time of using it. For diabetes patients with increased cardiovascular risk, aspirin ( $75-162 \mathrm{mg} /$ day) can be used for primary prevention after fully communicating with them on the benefits and potential risk of aspirin. Aspirin can reduce the risk of cardiovascular disease and death in patients with a history of myocardial infarction or stroke [23]. Due to systemic inflammatory reaction in patients with acute pancreatitis, their whole body is under the condition of hypercoagulability. Anti-platelet drugs can help prevent the expansion of formed thrombosis and prevent the formation of new thrombosis or embolism. In addition, they are mainly used for the prevention and treatment of thrombotic diseases. Guidelines for the use of anticoagulants and anti-platelet agents in acute pancreas have always been conservative, as drug use increases the risk of bleeding and mortality. In this cohort research, a subset of patients with cardiovascular disease, including those with chronic coronary syndrome and coronary heart disease, were eligible for anti-platelet therapy based on European and Chinese guidelines, and patient mortality or the incidence of adverse events can't be increased because of the use of anti-platelet therapy. Therefore, patients with cardiovascular diseases can take prophylactic anti-platelet drugs according to the guidelines on the basis of bleeding and platelet evaluation during the whole treatment process. When it comes to the deficiency of this paper, there is only a small amount of data in this study, therefore, multi-centered data is required to support the conclusion.

\section{Conclusion}

In the observational analysis in patients with acute pancreatitis, preventive anti-platelet therapy is not better than the preventive anti-platelet therapy in terms of reduced mortality, and simultaneously, it did not lead to reduced adverse events, in patients with cardiovascular under the acute pancreatitis and receiving anti-platelet agents, preventive anti-platelet therapy can also be used as a secondary drug for prevention. 


\section{Declarations}

\section{Ethical Approval}

This study was conducted in accordance with the declaration of Helsinki. All patients or family members involved in the study had signed informed consent. The study was approved by the Human Research Ethics Committees of The Affiliated Changzhou No.2 People's Hospital of Nanjing Medical University.

\section{Acknowledgements}

The authors wish to thank the study participants for their contribution to the research, as well as current and past investigators and staff.

\section{Funding}

The Project is funded by the Jiangsu Commission of Health (H2017004) and the Changzhou medical innovation team (CCX201807).

\section{Competing interests}

There is no conflict of interest in this paper.

\section{Reference}

[1] Boxhoom L, Voermans R,Bouwense s,Bruno M, Verdonk R ,et al .Acute pancreatitis[J] . Lancet ,2020,396(10252),726-734,doi:10.1016/s0140-6736(20)31310-6.

[2] Beyer G, Habtezion A ,Werner j , Lerch,M,\&Mayerle J.Chornic Pancreatitis[J].Lancet ,2020,396 (10249),499512.doi:10.1016/s0140-6736(20)31318-0.

[3] Mederos,M, Reber,H\&Girgis M.J.J.Acute Pancreatitis:A Review[J].JAMA,2021,325(4),382-390.doi: 10.1001/jama.2020.20317

[4] Banks P, Bollen T, Dervenis C, Gooszen H, Johnson C, Sarr M, Tsiotos G, Vege S, JG: Classification of acute pancreatitis-2012: revision of the Atlanta classification and definitions by international consensus.Gut. 2013, 62(1):102-111.doi:10.1136/gutjnl-2012-302779

[5].Easler J,Muddana V,Furlan A,et al. Portosplenomesenteric venous thrombosis in patients with acute pancreatitis is associated with pancreatic necrosis and usually has a benign course[J]. Clin Gastroenterol Hepatol,2014,12(5): 854-862. DOI:10.1016/j.cgh.2013.09.068.

[6] Crockett SD, Wani S, Gardner TB, et al. American Gastroenterological Association Institute guideline on initial management of acute pancreatitis[J]. Gastroenterology,2018,154(4):1096-1101. DOI:10.1053/j. gastro.2018.01.032.

[7] Iqbal U, Anwar H, Scribani M. Ringer's lactate versus normal saline in acute pancreatitis: a systematic review and Meta-analysis[J]. J Dig Dis, 2018, 19(6): 335-341. DOI: 10.1111/1751-2980.12606. 
[8] Stigliano S, Sternby H, de Madaria E, et al. Early management of acute pancreatitis: a review of the best evidence[J]. Dig Liver Dis, 2017, 49(6): 585-594. DOI: 10.1016/j.dld.2017.01.168.

[9] Colling ME, Tourdot BE,Kanthi Y.Inflammation, Infection and Venous Thromboembolism[J].Circ Res 2021 Jun 11;128(12)凶2017-2036.doi:10.1161/CIRCRESAHA.121.318225.

[10]Aslam R, Speck ER, Kim M, et al. Platelet Toll-like receptor expression modulates Lipopolysaccharid e-induced thrombocytopenia and tumor necrosis factor-alpha production in vivo [J]. Blood, 2006, 107(2): 637641.doi:10.1182/blood-2005-06-2202.

[11] Kissel K., Berber S, Nockher A, et al. Human platelets target dendritic cell differentiation and production of proinflammatory cytokines [J]. Transfusion, 2006, 46(5): 818-827. doi:10.1111/j.1537- 2995.2006.00802.x

[12] Michels M, DaniesIki LG, Vieira A, et al. CD40-CD40 ligand pathway is a major component of acute neuroinflammation and contributes to long-term cognitive dysfunction after sepsis [J]. Mol Med, 2015, 26(21): 219-226. doi:10.2119/molmed.2015.00070

[13] Rawish E, Nording $\mathrm{H}$,Munte t,LANGER HF,et.al Platelets as Mediators of Neuroinflammation and Thrombosis[J].Front Immunol.2020;11:584-631.doi:10.3389/fimmu.2020.548631

[14]Hicks SM, Lee CSM, Ali SA ,Choi PY,Gardiner EE,et al.The molecular basis of immune-based platelet disorders[J]. Clin Sci(Lond) 202011 13;134(21).doi:10.1042/CS20191101.

[15]Dapunt U, Maurer S, Giese T, et al. The macrophage inflammatory proteins MIP1a (CCL3) and MIP2a (CXCL2) in implant-associated osteomyelitis: linking inflammation to bone degradation [J]. Mediators of Inflammation, 2014, 44: 38.doi:10.1155/2014/728619.

[16] Henn V, Steinbach S, Buchner K, et al. The inflammatory action of CD40 ligand (CD154) expressed on activated human platelets is temporally limited by coexpressed CD40 [J]. Blood, 2001, 98(4): 1047-1054. doi:10.1182/blood.v98.4.1047.

[17] Fagerstam JP, Whiss PA, Strom M, et al. Expression of platelet P-selectin and detection of soluble P-selectin, NPY and RANTES in patients with inflammatory bowel disease [J]. Inflamm Res, 2000, 49 (9): 466 472.doi:10.1007/s000110050618.

[18] Craig NM, Angela AA, Lesley MC, et al. Emerging roles for platelets as immune and inflammatory cells [J]. Blood, 2014, 123(18): 2759-2767.doi:10.1186/1746-6148-10-87.

[19] Akyazi I, Eraslan E,Gulcubuk A,Ekiz EE, Cirakli ZL et al.Long-term aspirin pretreatment in the prevention of cerulein-induced acute pancreatitis in rats[J]. World J Gastroentrol2013 May 21;19(19) doi:10.3748/wjg.v19.i19.2894.

[20] Gao L Dong X Gong W Huang W Xue J et.al .Acinar cell NLRP3 inflammasome and gasdermin D (GSDMD) activation mediates pyroptosis and systemic inflammation in acute pancreatitis[J]. Br J pharmacol2021 Apr 19.doi:10.1111/bph.15499. 
[21] Trauer J, Muhi S, McBryde Es ,AlHarbi SA et al.Quantifying the Effects of Prior Acetyl-Salicylic Acid on Sepsis-Related Deaths: An Individual Patient Data Meta-Analysis Using Propensity Matching[J]. Crit Care Med 2017 Nov;45(11) .doi:10.1097/CCM.0000000000002654.

[22] Stolarek W, Kasprazak M, Sikora J, Sieminska E et al.High on-treatment platelet reactivity to aspirin in patients after myocardial infarction[J]. Biomed pharmacother 2022 Jan17;147.doi:10.1016/j.biopha.2022.112618.

[23] Writing committee members, Lawton JS , Tamis-Holland JE, Bangalore S et al.2021 ACC/AHA/SCAI Guideline for Coronary Artery Revascularization: A Report of the American College of Cardiology /American Heart Association Joint Committee on Clinical Practice Guidelines[M]. J AM Coll Cardol 2021 Dec 07.doi:10.1016/j.jacc.2021.09.006.

\section{Tables}

Table1: Baseline characteristics and clinical outcomes in pancreatitis patients treated with anti-platelet drug 
variable

Gender $n(\%)$

$$
\text { male }
$$

female

Age,(years)

$\mathrm{BMl},\left(\mathrm{kg} / \mathrm{m}^{2}\right)$

Hypertension, $\mathrm{n}(\%)$

Diabetes, $\mathrm{n}(\%)$

Dyslipidemia, $n(\%)$

Cardiovascular disease(CHD,CCS),n(\%)

Invasive ventilation, $\mathrm{n}(\%)$

$\mathrm{PLT},\left({ }^{*} 10^{9}\right)$

WBC, $\left({ }^{*} 10^{9}\right)$

$\mathrm{PT},\left({ }^{*} 10^{9}\right)$

Sapsii score

Oasis score

Sofa score

Gcs score

14-day mortality,n(\%)

28-day mortality,n(\%)

90-day mortality,n(\%)

$\mathrm{AKI}, \mathrm{n}(\%)$

ARDS, n $(\%)$

Live-dysfunction,n(\%)

Kidney-dysfunction,n(\%)

Heart-dysfunction,n(\%)

Septic shock,n(\%)

Urinary-tract-infection, $\mathrm{n}(\%)$

Intra-abdominal infectonal,n(\%)

Respiratory infection, $\mathrm{n}(\%)$

Blooding,n(\%)
No use drugs $(n=607)$

(1)

3

$331(54.53 \%)$

$276 \varangle 45.47 \% \rrbracket$

$62.26 \pm 45.67$

$28.59 \pm 8.44$

$248(40.85 \%)$

$165(27.18 \%)$

$54(8.89 \%)$

194(31.96\%)

152(25.04\%)

$296.82 \pm 150.90$

$12.15 \pm 5.96$

$15.49 \pm 6.12$

$37.02 \pm 15.80$

$32.66 \pm 9.38$

$5.4 \pm 3.71$

$13.83 \pm 2.45$

$58(9.55 \%)$

81(13.34\%)

98(16.14\%)

230(37.89\%)

$57(9.39 \%)$

$76(12.52 \%)$

243(40.03\%)

$140(23.06 \%)$

69(11.37\%)

82(13.51\%)

$167(27.51 \%)$

64(10.54\%)

$6(0.98 \%)$

Page 10/18 use drugs $(n=297) \quad p$-value

0.249

$174 \llbracket 58.58 \% \rrbracket$

$123(41.42 \%)$

$72.58 \pm 44.93 \quad 0.04$

$28.55 \pm 8.59$

0.957

$129(43.43 \%) \quad 0.46$

$83(27.94 \%) \quad 0.809$

$33(11.11 \%) \quad 0.298$

$116(39.06 \%) \quad 0.035$

$77(12.69 \%) \quad 0.774$

$319.01 \pm 158.54 \quad 0.041$

$12.16 \pm 5.60 \quad 0.967$

$15.41 \pm 5.10 \quad 0.855$

$35.2 \pm 14.9 \quad 0.97$

$32.25 \pm 9.48 \quad 0.539$

$4.69 \pm 3.50 \quad 0.04$

$13.96 \pm 2.15 \quad 0.444$

$14(4.71 \%) \quad 0.012$

$24(8.08 \%) \quad 0.02$

$39(13.13 \%) \quad 0.235$

$145(48.82 \%) \quad 0.02$

$26(8.75 \%) \quad 0.756$

30(10.10\%) $\quad 0.288$

$127(42.76 \%) \quad 0.433$

68(28.90\%) $\quad 0.955$

34(11.45\%) $\quad 0.971$

$52(17.51 \%) \quad 0.112$

100(33.67\%) $\quad 0.057$

$22(7.41 \%) \quad 0.131$

$3(0.101 \%)$

0.987 
BMI:body mass index;CHD:coronary heart disease;CCS:Chronic Coronary Syndrome ;PLT

\Platelet;WBC:White Blood Cell ;PT:Prothrombin time ;Saps-ii score=simplified Acute physiology score II ;Sofa score=Sequential Organ Failure Assessment;GAS=Glasgow Coma scale;Oasis score=Oxford Acute severity of illness score;AKI=Acute Renal Injury;ARDS=Acute Respiratory Distress Syndrome

Table2 Distribution of clinically relevant variables and adverse events before and after propensity score matching in patients treated with anti-platelet drug 


\begin{tabular}{|c|c|c|c|c|c|c|}
\hline variable & Pre-PSM & & & Post-PSM & & \\
\hline Baseline data & $\begin{array}{l}\text { No Use } \\
\text { drugs }(n=607)\end{array}$ & $\begin{array}{l}\text { Use } \\
\text { drugs(n=297) }\end{array}$ & $\begin{array}{l}\mathrm{p}- \\
\text { value }\end{array}$ & $\begin{array}{l}\text { No Use } \\
\text { drugs }(n=297)\end{array}$ & $\begin{array}{l}\text { Use } \\
\text { drugs(n=297) }\end{array}$ & $\begin{array}{l}\mathrm{p}- \\
\text { value }\end{array}$ \\
\hline Gender n(\%) & & & 0.249 & & $72.58 \pm 44.93$ & 0.99 \\
\hline male & $331(54.53 \%)$ & $174 \llbracket 58.58 \% \rrbracket$ & & $154 \llbracket 51.85 \% \rrbracket$ & $174 ه 58.59 \% \rrbracket$ & \\
\hline female & $276 \rrbracket 45.47 \% \rrbracket$ & $123(41.42 \%)$ & & $143 \rrbracket 48.15 \% \rrbracket$ & $123 \llbracket 41.41 \% \bigotimes$ & \\
\hline Age,years & $62.26 \pm 45.67$ & $72.58 \pm 44.93$ & 0.04 & $68.50 \pm 57.68$ & $72.58 \pm 44.93$ & 0.337 \\
\hline $\begin{array}{l}\text { Hypertension, } \\
\mathrm{n}(\%)\end{array}$ & $28.59 \pm 8.44$ & $28.55 \pm 8.59$ & 0.957 & $126 \rrbracket 42.42 \% \rrbracket$ & $129 \llbracket 43.43 \% \rrbracket$ & 0.804 \\
\hline Diabetes, n (\%) & 165(27.18\%) & $83(27.94 \%)$ & 0.809 & $80(26.93 \%)$ & 83囚27.95\%】 & 0.991 \\
\hline $\begin{array}{l}\text { Dyslipidemia, n } \\
\text { (\%) }\end{array}$ & $54(8.89 \%)$ & $33(11.11 \%)$ & 0.298 & $24(7.07 \%)$ & $33(11.11 \%)$ & 0.21 \\
\hline Coronary,n(\%) & 194(31.96\%) & 116(39.06\%) & 0.035 & 119(40.06\%) & 116(39.06\%) & 0.801 \\
\hline $\begin{array}{l}\text { Invasive } \\
\text { ventilation,n(\%) }\end{array}$ & $152(25.04 \%)$ & 77(12.69\%) & 0.774 & $73 \rrbracket 24.58 \% \rrbracket$ & $77 \rrbracket 25.93 \% \rrbracket$ & 0.706 \\
\hline $\mathrm{PLT},\left({ }^{\star} 10^{9}\right)$ & $296.82 \pm 150.90$ & $319.01 \pm 158.54$ & 0.041 & $299.32 \pm 152.47$ & $319.01 \pm 158.54$ & 0.124 \\
\hline WBC, $\left({ }^{\star} 10^{9}\right)$ & $12.15 \pm 5.96$ & $12.16 \pm 5.60$ & 0.967 & $12.06 \pm 6.05$ & $12.17 \pm 5.61$ & 0.356 \\
\hline $\mathrm{PT},\left(\star 10^{9}\right)$ & $15.49 \pm 6.12$ & $15.41 \pm 5.10$ & 0.855 & $14.90 \pm 3.62$ & $15.41 \pm 5.10$ & 0.356 \\
\hline Saps-ii score & $37.02 \pm 15.80$ & $35.2 \pm 14.9$ & 0.97 & $38.17 \pm 15.24$ & $35.20 \pm 14.90$ & 0.016 \\
\hline Oasis score & $32.66 \pm 9.38$ & $32.25 \pm 9.48$ & 0.539 & $33.16 \pm 8.95$ & $32.25 \pm 9.48$ & 0.225 \\
\hline Sofa score & $5.4 \pm 3.71$ & $4.69 \pm 3.50$ & 0.04 & $5.59 \pm 3.78$ & $4.69 \pm 3.50$ & 0.03 \\
\hline Gcs score & $13.83 \pm 2.45$ & $13.96 \pm 2.15$ & 0.444 & $13.6 \pm 2.79$ & $13.96 \pm 2.15$ & 0.079 \\
\hline $\begin{array}{l}\text { 14-day } \\
\text { mortality,n(\%) }\end{array}$ & $58(9.55 \%)$ & $14(4.71 \%)$ & 0.012 & 26(8.75\%) & $14(4.71 \%)$ & 0.049 \\
\hline $\begin{array}{l}\text { 28-day } \\
\text { mortality,n(\%) }\end{array}$ & $81(13.34 \%)$ & $24(8.08 \%)$ & 0.02 & $39(13.13 \%)$ & $24(8.08 \%)$ & 0.046 \\
\hline $\begin{array}{l}\text { 90-day } \\
\text { mortality,n(\%) }\end{array}$ & $98(16.14 \%)$ & $39(13.13 \%)$ & 0.235 & $47(15.82 \%)$ & $39(13.13 \%)$ & 0.351 \\
\hline $\mathrm{AKI}, \mathrm{n}(\%)$ & $230(37.89 \%)$ & 145(48.82\%) & 0.02 & 114(38.38\%) & 145(48.82\%) & 0.01 \\
\hline ARDS,n(\%) & $57(9.39 \%)$ & $26(8.75 \%)$ & 0.756 & $23(7.74 \%)$ & $26(8.75 \%)$ & 0.665 \\
\hline $\begin{array}{l}\text { Live- } \\
\text { dysfunction,n(\%) }\end{array}$ & $76(12.52 \%)$ & $30(10.10 \%)$ & 0.288 & $35(11.78 \%)$ & $30(10.10 \%)$ & 0.511 \\
\hline $\begin{array}{l}\text { Kidney- } \\
\text { dysfunction,n(\%) }\end{array}$ & $243(40.03 \%)$ & $127(42.76 \%)$ & 0.433 & $125(42.08 \%)$ & $127(42.76 \%)$ & 0.868 \\
\hline $\begin{array}{l}\text { Heart- } \\
\text { dysfunction,n(\%) }\end{array}$ & $140(23.06 \%)$ & $68(28.90 \%)$ & 0.955 & $69(23.23 \%)$ & $68(22.89 \%)$ & 0.922 \\
\hline
\end{tabular}




\begin{tabular}{lcccccc}
$\begin{array}{l}\text { Septic } \\
\text { shock,n(\%) }\end{array}$ & $69(11.37 \%)$ & $34(11.45 \%)$ & 0.971 & $32(10.77 \%)$ & $34(11.45 \%)$ & 0.794 \\
\hline $\begin{array}{l}\text { Urinary-tract- } \\
\text { infection,n(\%) }\end{array}$ & $82(13.51 \%)$ & $52(17.51 \%)$ & 0.112 & $37(12.45 \%)$ & $52(17.51 \%)$ & 0.085 \\
\hline $\begin{array}{l}\text { Intra-abdominal } \\
\text { infection,n(\%) }\end{array}$ & $167(27.51 \%)$ & $100(33.67 \%)$ & 0.057 & $82(27.60 \%)$ & $100(33.67 \%)$ & 0.109 \\
\hline $\begin{array}{l}\text { Respiratory } \\
\text { infection,n(\%) }\end{array}$ & $64(10.54 \%)$ & $22(7.41 \%)$ & 0.131 & $32(10.77 \%)$ & $22(7.41 \%)$ & 0.119 \\
\hline Blooding,n(\%) & $6(0.98 \%)$ & $3(0.101 \%)$ & 0.987 & $4(1.34 \%)$ & $3(1.01 \%)$ & 0.942
\end{tabular}

Table3 Impact of use drug vs. No use drug on the event risk at Cox analysis

\begin{tabular}{|c|c|c|c|c|}
\hline Event risk & Pre-PSM & & Post-PSM & \\
\hline & $\mathrm{HR}(95 \% \mathrm{Cl})$ & P-Value & $\mathrm{HR}(95 \% \mathrm{Cl})$ & $\mathrm{p}$-value \\
\hline 14-day mortality Unadjusted & $2.063 \rrbracket 1.150-3.701 \rrbracket$ & 0.015 & $1.854 \rrbracket 0.964-3.567 \rrbracket$ & 0.064 \\
\hline Adjusted model 1 & $2.189 \rrbracket 1.045-4.583 \rrbracket$ & 0.038 & $1.418 \rrbracket 0.593-3.395 \rrbracket$ & 0.433 \\
\hline Adjusted model 2 & $2.185 \rrbracket 1.021-4.667 \rrbracket$ & 0.044 & $1.213 \otimes 0.483-3.049 \rrbracket$ & 0.681 \\
\hline 28-day mortality Unadjusted & $1.702 \rrbracket 1.079-2.686 \rrbracket$ & 0.22 & $1.654 \rrbracket 0.992-2.756 \rrbracket$ & 0.054 \\
\hline Adjusted model 1 & $2.397 \rrbracket 1.269-4.525 \rrbracket$ & 0.007 & $1.821 \rrbracket 0.884-3.751 \rrbracket$ & 0.104 \\
\hline Adjusted model 2 & $2.811 \rrbracket 1.473-5.364 \rrbracket$ & 0.002 & $1.735 \rrbracket 0.815-3.693 \rrbracket$ & 0.153 \\
\hline
\end{tabular}

$\mathrm{HR}=$ Hazard Ratio ;Cl: confidence interval PSM:Propensity matching analysis

Table 4 .Association between treatment with use drug vs. No use drug and mortality in subgroups. 
Pre-PSM

post-PSM

\begin{tabular}{|c|c|c|c|c|c|}
\hline Subgroups & & $\mathrm{HR}(95 \% \mathrm{Cl})$ & $\begin{array}{l}\text { P- } \\
\text { Value }\end{array}$ & $\mathrm{HR}(95 \% \mathrm{Cl})$ & $\begin{array}{l}\text { P- } \\
\text { Value }\end{array}$ \\
\hline \multirow[t]{2}{*}{ Sex } & male & $\begin{array}{l}3.391(1.318- \\
8.720)\end{array}$ & 0.011 & $\begin{array}{l}2.541(0.883- \\
7.351)\end{array}$ & 0.84 \\
\hline & female & $\begin{array}{l}0.471(0.619- \\
2.821)\end{array}$ & 0.471 & $\begin{array}{l}1.409(0.610- \\
3.256)\end{array}$ & 0.422 \\
\hline \multirow[t]{2}{*}{ Age,yrs } & $\geq 60$ & $\begin{array}{l}1.928(1.015- \\
3.662)\end{array}$ & 0.045 & $\begin{array}{l}1.761(0.838- \\
3.701)\end{array}$ & 0.135 \\
\hline & $\nabla 60$ & $\begin{array}{l}7.650(1.035- \\
56.551)\end{array}$ & 0.46 & $\begin{array}{l}6.618(0.847- \\
51.686)\end{array}$ & 0.072 \\
\hline \multirow[t]{2}{*}{ BMI,kg/m2 } & $\mathrm{BMI} \geq 25$ & $\begin{array}{l}2.178 \rrbracket 0.890- \\
5.328 \rrbracket\end{array}$ & 0.088 & $\begin{array}{l}1.312(0.441- \\
3.905)\end{array}$ & 0.625 \\
\hline & BMII25 & $\begin{array}{l}1.644 \rrbracket 0.459- \\
5.894 \rrbracket\end{array}$ & 0.445 & $\begin{array}{l}1.467(0.351- \\
6.138)\end{array}$ & 0.6 \\
\hline \multirow[t]{2}{*}{ Hypertension } & Yes & $\begin{array}{l}2.085(0.980- \\
4.789)\end{array}$ & 0.083 & $\begin{array}{l}1.827(0.719- \\
4.460)\end{array}$ & 0.205 \\
\hline & No & $\begin{array}{l}2.072(0.910- \\
4.717)\end{array}$ & 0.81 & $\begin{array}{l}1.892(0.755- \\
4,742)\end{array}$ & 0.174 \\
\hline \multirow[t]{2}{*}{ Diabetes } & Yes & $\begin{array}{l}1.765(0.904- \\
3.446)\end{array}$ & 0.096 & $\begin{array}{l}2.106 \rrbracket 0.527- \\
8.420 \rrbracket\end{array}$ & 0.292 \\
\hline & No & $\begin{array}{l}3.173(0.925- \\
10.772)\end{array}$ & 0.64 & $\begin{array}{l}1.783 \bowtie 0.848- \\
3.746 \rrbracket\end{array}$ & 0.127 \\
\hline \multirow[t]{2}{*}{ AKI } & Yes & $\begin{array}{l}1.436(0.473- \\
4.364)\end{array}$ & 0.523 & $\begin{array}{l}2.589(0.988- \\
5.567)\end{array}$ & 0.356 \\
\hline & No & $\begin{array}{l}2.915(1.465- \\
5.801)\end{array}$ & 0.002 & $\begin{array}{l}1.275(0.360- \\
4.519)\end{array}$ & 0.706 \\
\hline \multirow[t]{2}{*}{ ARDS } & Yes & $\begin{array}{l}1.376(0.278- \\
6.817)\end{array}$ & 0.696 & $\begin{array}{l}1.134(0.160- \\
8.055)\end{array}$ & 0.900 \\
\hline & No & $\begin{array}{l}2.174 \rrbracket 1.159- \\
4.078 \rrbracket\end{array}$ & 0.015 & $\begin{array}{l}1.975(0.982- \\
3.965)\end{array}$ & 0.56 \\
\hline \multirow[t]{2}{*}{ Hyperlipemia } & Yes & $\begin{array}{l}1.225(0.111- \\
13.510)\end{array}$ & 0.868 & $\begin{array}{l}1.405(0.088- \\
22.459)\end{array}$ & 0.81 \\
\hline & No & $\begin{array}{l}2.907 \rrbracket 1.146- \\
3.839 \rrbracket\end{array}$ & 0.16 & $\begin{array}{l}1.855(0.945- \\
3.644)\end{array}$ & 0.73 \\
\hline \multirow[t]{2}{*}{$\begin{array}{l}\text { Cardiovascular } \\
\text { disease(CHD,CCS),n(\%) }\end{array}$} & Yes & $\begin{array}{l}2.460(1.157- \\
5.233)\end{array}$ & 0.019 & $\begin{array}{l}2.106 \rrbracket 1.013- \\
4.920 \rrbracket\end{array}$ & 0.830 \\
\hline & No & $\begin{array}{l}1.418(0.545- \\
3.690)\end{array}$ & 0.474 & $\begin{array}{l}1.323 \rrbracket 0.459- \\
3.812 \rrbracket\end{array}$ & 0.605 \\
\hline \multirow[t]{2}{*}{ Invasive ventilation } & Yes & $\begin{array}{l}2.386 \rrbracket 0.807- \\
7.050 \rrbracket\end{array}$ & 0.116 & $\begin{array}{l}1.923(0.563- \\
6.570)\end{array}$ & 0.297 \\
\hline & No & $\begin{array}{l}1.944 \varangle 0.970- \\
\text { Page } 14 / 18\end{array}$ & 0.641 & 1.833(0.846- & 0.124 \\
\hline
\end{tabular}




\begin{tabular}{|c|c|c|c|c|c|}
\hline & & $3.894 \rrbracket$ & & 3.972) & \\
\hline \multirow[t]{2}{*}{ Liver-dysfunction } & Yes & $\begin{array}{l}1.434(0.298- \\
6.903)\end{array}$ & 0.653 & $\begin{array}{l}1.313(0.219- \\
7.856)\end{array}$ & 0.766 \\
\hline & No & $\begin{array}{l}2.169(1.155- \\
4.073)\end{array}$ & 0.016 & $\begin{array}{l}1.943(0.962- \\
3.926)\end{array}$ & 0.064 \\
\hline \multirow[t]{2}{*}{ kidney_dysfunction } & Yes & $\begin{array}{l}1.335(0.518- \\
3.440)\end{array}$ & 0.015 & $1.210(0.407-3.60)$ & 0.730 \\
\hline & No & $\begin{array}{l}2.560(1.202- \\
5.453)\end{array}$ & 0.55 & $\begin{array}{l}2.332(0.998- \\
5.362)\end{array}$ & 0.051 \\
\hline \multirow[t]{2}{*}{ heart-dysfunction } & Yes & $\begin{array}{l}1.060(0.403- \\
2.788)\end{array}$ & 0.07 & $\begin{array}{l}0.826(0.252- \\
2.707)\end{array}$ & 0.753 \\
\hline & No & $\begin{array}{l}2.807(1.322- \\
5.962)\end{array}$ & 0.906 & $\begin{array}{l}2.623(0.687- \\
5.956)\end{array}$ & 0.132 \\
\hline
\end{tabular}

Figures 


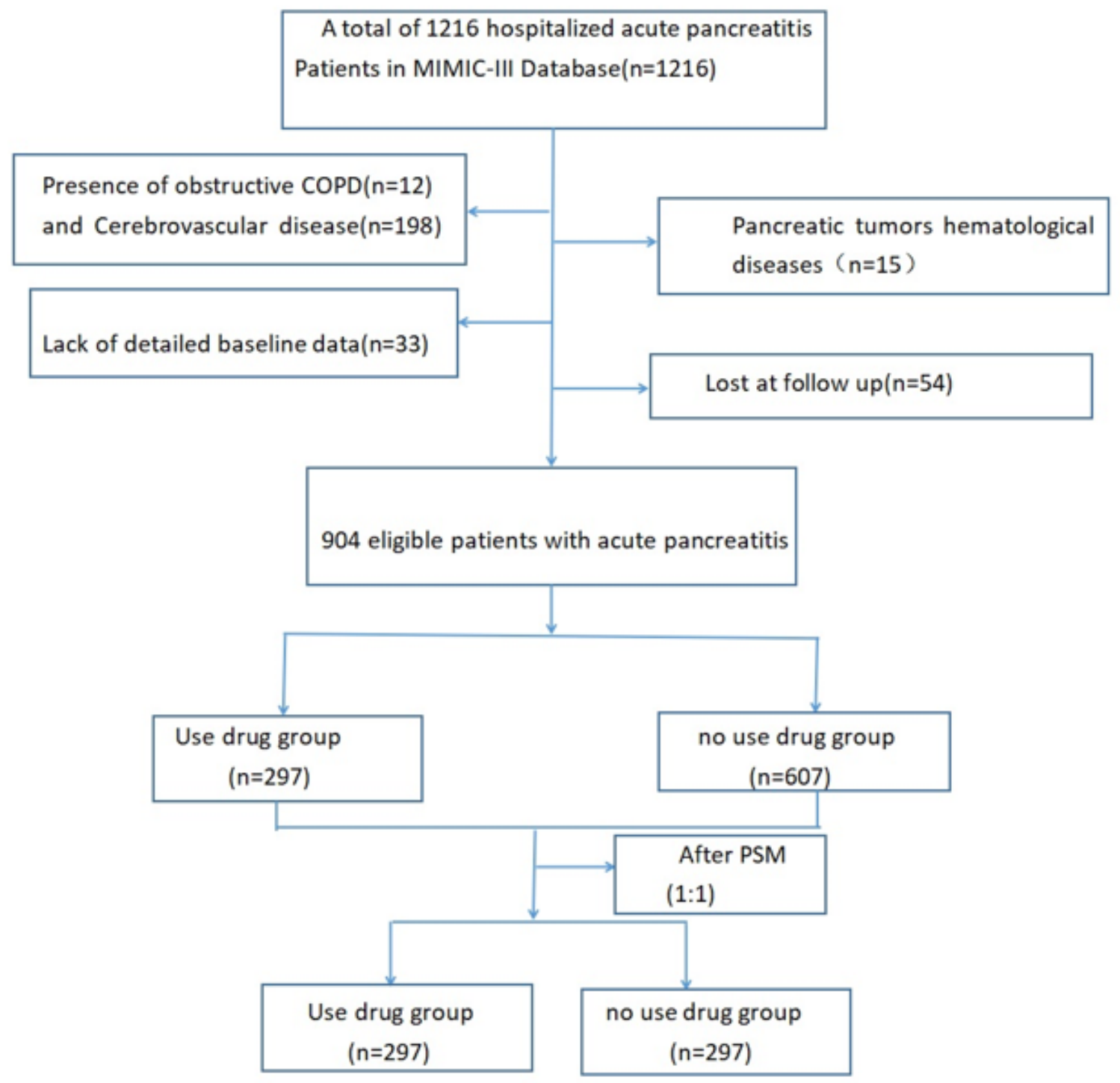

Figure 1

Study flowchart. 


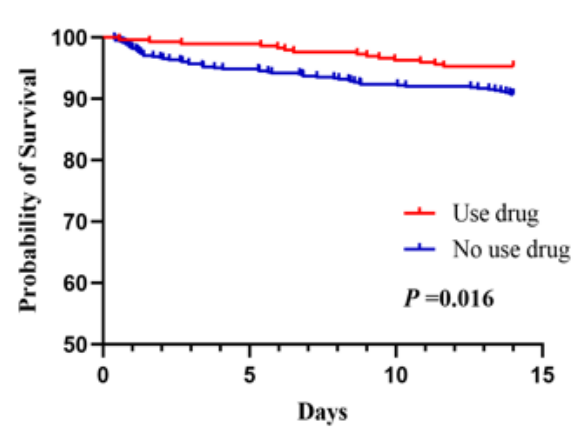

(a)

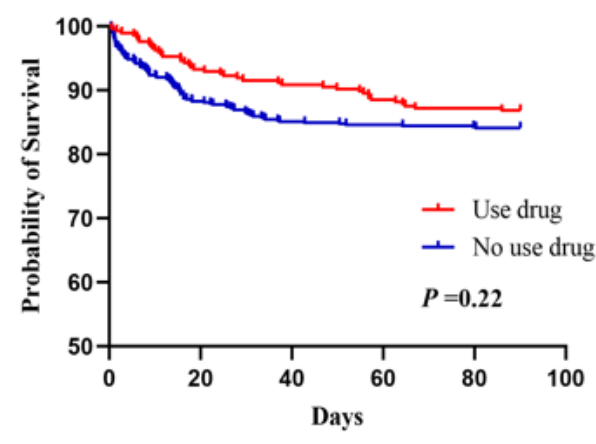

(c)

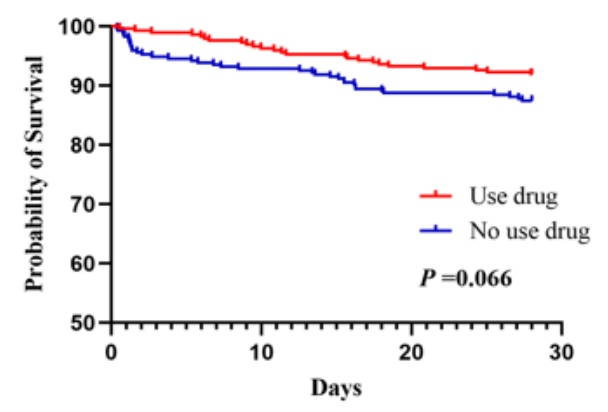

(e)

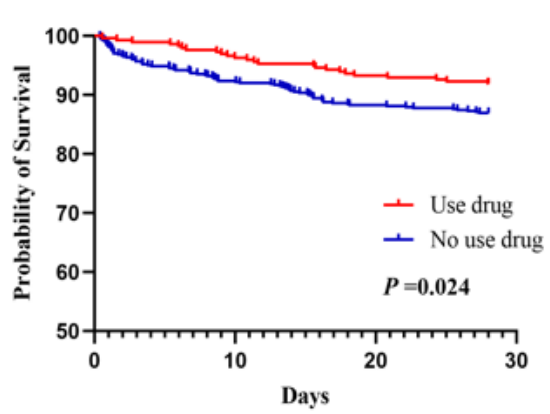

(b)

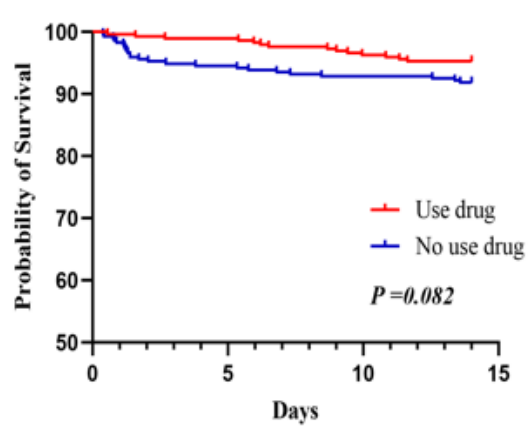

(d)

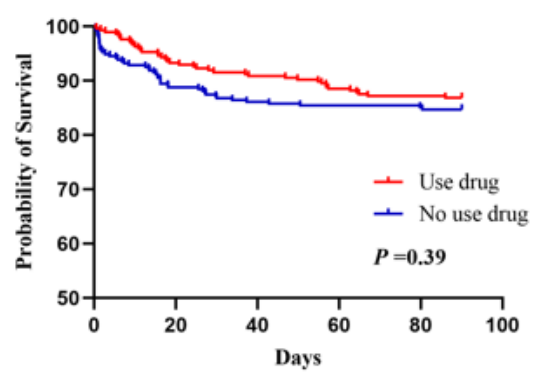

(f)

\section{Figure 2}

survival curve in the two groups before and after PSM. Before PSM(a-c). a the 14-day mortality(use drug group vs. No use drug group). $\mathbf{b}$ the 28-days mortality $\mathbf{c}$ the 90 -days mortality.after PSM(d-f).d the 14-day mortality(use drug group vs. No use drug group). e.the 28-days mortality. f. the 90 -days mortality.

\section{Supplementary Files}

This is a list of supplementary files associated with this preprint. Click to download. 
- SupplementaryMaterialPostPSM.xIsx

- SupplementaryMaterialPrePSM.xls

- originalfile.xlsx 